\title{
¿Constitución heredada es constitución legitimada?
}

\section{Carlos López Dawson*}

Recibido: 07 febrero

Dictaminado: 09 mayo

\section{Resumen}

Las Constituciones políticas resultan de procesos de demandas por el reconocimiento de derechos y por lo mismo tales derechos responden a su tiempo y circunstancias. Una Constitución es en estricto rigor una expresión de la fuerza social de un momento. La Constitución es una expresión del derecho y en el siglo XXI en Chile no puede ser sino una que garantice la democracia, la participación y los derechos humanos. No obstante, se aplica una Constitución originada bajo dictadura con valores no democráticos que no garantizan la vigencia de los derechos humanos, y reformada con quórums no democráticos. ¿Ello la legitima?

Palabras clave: Constitución, Derechos Humanos, Procesos Constitucionales, Asamblea Constituyente.

\section{¿Constitution inherited is constitution legitimized?}

\begin{abstract}
The Political Constitutions are processes of demands by the recognition of rights and by the msim such rights respond to time and circumstances. Strictly a Constitution is an expression of the social force of a moment The Constitution is an expression of the right and in the 21 st century in Chile may thereby be but one that guarantees democracy, participation and human rights. However, a Constitution originated under dictatorship with non-democratic values that do not guarantee the validity of human rights and reformed with non-democratic quorums is applied. Does this legitimize it?
\end{abstract}

\footnotetext{
* Docente Investigador de la Universidad Autónoma de Chile, lopezdawson@gmail.com
} 
Key words: Constitution, Human Rights, Constitutional Processes, Ponstituent Assembly.

\section{Sumario}

I Introduccion; II La emergencia del estado; 2.1 Recuperar la democracia; 2.2 Estado de derecho y neoliberalismo; 2.3 Atributos esenciales de un estado de derecho en el siglo XXI; $2.4 \mathrm{El}$ control y responsabilidad de los gobernantes; III Reafirmacion historica del principio de legalidad; 3.1 Origen y caracteristicas de la constitucion de 1980; 3.2 La constitucion politica y los derechos y deberes; $3.3 \mathrm{El}$ derecho internacional de los derechos humanos y el derecho constitucional; 3.4 Los limites de la soberania; IV Las caracteristicas de la constitucion; 4.1 Presencia de la constitucion en nuestra vida cotidiana; 4.2 Principales criticas; 4.3 Reformas y una nueva constitucion; 4.4 Educacion civica y una nueva cultura; 4.5 Modos de cambio constitucional; V Concluciones; Bibliografía

\section{Introducción}

Los Derechos Humanos son progresivos, una vez reconocido un derecho no se puede volver atrás legítimamente. Ello se explica entre otras causas por el estado del derecho internacional, el estado actual de las relaciones internacionales y la universalización de la cultura, por lo que no corresponde decir que un proceso constituyente en Chile comienza con una hoja en blanco. En efecto, el derecho internacional tiene como su centro el respeto y promoción de los derechos humanos como obligación de todos los Estados sean o no miembros de las Naciones Unidas ${ }^{1}$. Es un hecho que los intercambios de todo tipo son crecientes en el mundo de hoy, cuyos efectos se están haciendo sentir cada día más en el desarrollo económico, social, aun cuando surgen intentos por el proteccionismo comercial, la discriminación ideológica, la persecución por motivos religiosos, y el rechazo a los movimientos migratorios. Chile es, de alguna manera, pionero y ha visto su desarrollo económico íntimamente dependiente de los intercambios principalmente de comercio y financiero y últimamente turístico ${ }^{2}$. De allí que se

1 Carta de San Francisco, Capítulo VII.

2 Ver por ejemplo Elkin, N, (Noviembre 1994), Las normas internacionales del trabajo y la integración regional económica. en Integración Latinoamericana (Buenos Aires. INTAL), nº 19, 205, 
pueda calificar como un país dependiente. No obstante, hay un aspecto que ha tomado particular notoriedad a propósito de recientes crisis políticas en diferentes países de América Latina, es la denominada cláusula democrática presente hoy en diversos instrumentos internacionales, en el sistema interamericano, en el Acuerdo del Mercosur y en la Unasur. La firma del Acuerdo del Mercosur por el entonces jefe de Estado de Paraguay ha sido uno de los argumentos de la acusación constitucional que terminó con su destitución ${ }^{3}$. En efecto, sus acusadores criticaron la firma del Protocolo de Usuaia II, que autoriza a los países del Mercado Común del Sur (MERCOSUR) a bloquear a los países en los que se registren amenazas contra el orden democrático, al considerar que "constituye un atentado contra la soberanía de Paraguay"4.

En este mismo espíritu democratizador que emana de la Carta de Naciones Unidas, en marzo de 1995 los Jefes de Estado y de Gobierno de todos los países miembros de las Naciones Unidas firmaron en Copenhague la Declaración sobre Desarrollo Social y acordaron el Programa de Acción que se propone contribuir a la democratización en un contexto de respeto de los derechos humanos. E1 décimo y último compromiso de la Declaración de Copenhague señala que los gobiernos del mundo se obligaron a:

"mejorar y fortalecer con espíritu de coparticipación, el marco de la cooperación internacional, regional y subregional para el desarrollo social por medio de las Naciones Unidas y de otras instituciones multilaterales"

El Plan de Acción de Copenhague cuyo objetivo es dar cumplimiento al mencionado compromiso, expresa la voluntad de la comunidad internacional y, por lo tanto, de los Estados firmantes de adoptar medidas y mecanismos apropiados en el ámbito nacional y regional, así como una serie de disposiciones

3 Quirós, L, (2013) "La destitución de Fernando Lugo y la crisis politica de los Ejecutivos en America Latina (2000-2012)."

Available at: http://works.bepress.com/ludmila_quiros/8/, y Kersffeld,D. La UNASUR y su accionar frente a conflictos internacionales: http://search.proquest.com/openview/9efd2d768b8d03885dd56e55c2a2dcf8/1?pqorigsite $=$ gscholar $\& \mathrm{cbl}=27928$

4 http://dossiergf.wordpress.com/2012/06/22/la-acusacion-contra-lugo-se-basa-en-cinco-actuaciones-de-sugobierno-y-pide-un-proceso-penal/ 
a ser ejecutadas en el plano internacional.

La observancia de los derechos humanos, incluido el respeto a la democracia, ha sido acordada también por los Estados miembros de la Organización de Estados Americanos como una condición de pertenencia al sistema interamericano, sin relacionarlo directamente con los intercambios comerciales ni con los procesos de integración económica. Por otra parte, debido a la complejidad del tema se han preferido los ámbitos de relaciones política, culturales, de seguridad ciudadana, por lo que no se ha incursionado con detenimiento, por ejemplo, en otros más relacionados con el bienestar como son los derechos laborales, previsionales y de seguridad social de los trabajadores, derechos ciudadanos, derechos del consumidor, entre otros, que constituyen hoy en día preocupaciones y demandas de la sociedad civil que se expresan en diferentes niveles ${ }^{5}$. Sin embargo, todos los derechos humanos tienen el mismo rango, no hay derechos más importantes que otros, son todos igualmente exigibles ${ }^{6}$.

\section{La emergencia del Estado}

En los procesos culturales internacionales, el actor por excelencia es el gobierno nacional en representación del Estado. Esta representación se realiza dentro de un sistema que conlleva al debilitamiento o transformación del Estado tradicional, toda vez que este tipo de proceso conduce a una renuncia de ciertas atribuciones soberanas, sino de todas en el largo plazo, en un proceso donde la ciudadanía tiene una intervención lejana y muchas veces desinformada. De esta manera, desde el momento en que surge la Organización de las Naciones Unidas, la forma tradicional del Estado sufre una mutación para adquirir un nuevo perfil que se caracteriza por una institucionalidad democrática diferente toda vez que, por ahora, las decisiones se toman sin la participación directa de los ciudadanos

\footnotetext{
5 Varias publicaciones académicas se preocupan de estos temas. A manera de ilustración puede consultarse la obra editada por Stahringer de Caramuti, O, (1998), El MERCOSUR en el Siglo XXI., Buenos Aires, Ediciones Ciudad Argentina, 591 págs. ( varios autores, por ejemplo Da Silva, C, Globalización y Regionalismo versus trabajo y desempleo. Notas de fin de milenio, pp. 107-134.). Ver Revista de Derecho del Mercosur, contiene artículos relativos. Varias ONGs. exigen la inclusión de los derechos humanos en los acuerdos de integración económica, particularmente respecto del ALCA. Ver al respecto www.redchile.com.

6 http://www.un.org/womenwatch/daw/beijing/pdf/BDPfA\%20S.pdf
} 
pero que al mismo tiempo involucran a ciudadanos de diferentes Estados, carácter que se acentúa en los acuerdos internacionales, por ejemplo en los de comercio internacional.

Sin perjuicio de la función que cumple como organizador de la comunidad, el Estado ha sido profundamente cuestionado debido particularmente al carácter estamental o clasista que ha revestido a pesar del triunfo de la Ilustración que combatió precisamente la desigualdad y la discriminación legal, sin que en la práctica lograra en plenitud sus objetivos revolucionarios, lo que explica el surgimiento del pensamiento crítico, como el de Marx para quien el Estado era expresión de la manera como se desarrollaba históricamente la economía, es decir la forma como se adquiere la propiedad de los medios de producción y como estos se utilizan, configurando el sistema capitalista, un sistema social dividido en clases sociales que se reparten el producto de manera desigual en virtud de la apropiación de la plusvalía por el capitalista, despojando al trabajador de su parte sin que la mayoría de los ciudadanos tengan canales de participación política que permita cambiar la situación. Esta estructura social se refleja en el Estado y lo convierte en expresión de la clase dominante, actuando por lo tanto en función del marco institucional o del sistema impuesto por el modo de producción. De esta manera, en una sociedad dividida en clases sociales habrá concepciones dominantes propias de la clase propietaria de los medios de producción?

Es indudable que el Estado reproduce el carácter objetivo de las relaciones de la formación social, cualquiera sea su característica esté o no dividida en estamentos, castas o clases y esto por cuanto toda institución inserta y expresión de un sistema social no hace sino que reproducir en su seno y en su función las relaciones sociales dominantes. De esta manera las instituciones estatales representan objetivamente los intereses de clases o de fracciones de clases dominantes en un momento dado. De modo que, cuando existe un cierto equilibrio de clases o lo que se ha dado en llamar Estado de Compromiso, la administración en general y la Justicia en particular logran cierta independencia con relación a los poderes políticos y económicos, pero siguen determinadas en su función social

7 Marx, K, (1987), El Capital, - tomo II, Pág. 154. Marx/ Engels "Manifiesto Comunista" Engels, "principios del comunismo", en http://www.monografias.com/trabajos5/tekarl/tekarl.shtml. Marx k, (1857), introducción general a la crítica de la economía política Pág. 11 
por el modo de producción vigente. De otra manera dejarían de ser instituciones de ese Estado ${ }^{(8)}$. Es indudable que un Estado incapaz de lograr un pacto social sería inaceptable en los tiempos actuales y la mejor demostración de ello está en las guerras civiles que se desarrollan en diferentes lugares o la inestabilidad que afecta a los regímenes totalitarios o dictatoriales, como ha quedado largamente demostrado en las experiencias de América Latina y en la Europa del Este. De allí que el problema se puede trasladar al debate constitucional, lo que requiere necesariamente un marco democrático, no formal o aparente, sino real. De manera que cuando no existe tal contexto democrático no es solo un problema político sino que es en realidad una crisis cultural completa ${ }^{(9)}$.

Por otra parte, la crítica al régimen no consensual o no contractual es compartida por diferentes corrientes políticas, incluidos el marxismo y el liberalismo, por considerarlo un sistema que obstaculiza el desarrollo de la libertad y el ejercicio de los derechos fundamentales ${ }^{(10)}$ desde la perspectiva de las libertades públicas.

Elprimer esfuerzo por construir la unidad en el Estado consistió en asignarle el papel de representación de una comunidad dominante, la que era considerada toda la nación aún cuando ocuparan ese territorio otros pueblos con idiomas, culturas e historias distintas, cuyo ejemplo fue la Francia decimonónica. Derivación de esta

8 Althouser, L, (1968): Montesquieu, la politique et l'histoire; París, PUF, cap. V. También, Kirchheimer, Otto, (1968). Justicia politica. Baires. Ed. T. pág. 191

9 Existe una abundante bibliografía respecto de la crisis de los sistemas judiciales en América Latina como expresión del conflicto profundo de los sistemas políticos.. Entre otras se pueden destacar las obras publicadas por la Comisión Andina de Juristas (Ver su página WEB). Hay, por cierto, en el caso de Chile, varias excepciones a este comportamiento, como ha ocurrido en las investigaciones del denominado caso Lonquén (Ministro Bañados); sobre desaparecidos (Ministro Jordan); el caso conocido como los "Chacales de Calama"; el caso Insunza Ortega (Ministros Libedinsky y Chaigneau), entre otros. Debemos mencionar la actitud decidida asumida en 1985 por el entonces Presidente de la Corte Suprema, don Rafael Retamal, la del fallecido Ministro José Cánovas en la investigación de la muerte de Parada, Guerrero y Nattino, la del Ministro Carlos Cerda, quien estuvo por rechazar el decreto ley de amnistía en casos de crímenes de lesa humanidad. Al término de la dictadura la Corte Suprema ha establecido una lógica de justicia toda vez que, rechazando un recurso de amparo interpuesto por Arellano Stark y otros, contra resolución del Ministro en Visita Juan Guzmán, ha resuelto que no procede la cosa juzgada ni la prescripción ni la amnistía cuando no se ha determinado el destino del detenido ilegalmente, que en realidad era un secuestrado, por cuanto en este caso se trata de un delito continuo (El Mercurio, 19 de julio de 1999). Este es un cambio sustancial en beneficio de los derechos humanos. Ver Atria y otros, (1990), Chile, la Memoria Prohibida, Santiago, Dolmen,. Montealegre Klenner, H,(1979), La seguridad del Estado y los derechos humanos, Santiago de Chile, Dolmen. 10 Montealegre Klenner, H, (1995), p. 35. 
idea es la de soberanía, la que se va desarrollando con el surgimiento del derecho de gente y con el fortalecimiento de otras comunidades y que fuera teorizada por los contractualistas, y es la que se pretende en el constitucionalismo en América Latina que, como sabemos, está poblada por comunidades originarias que han debido luchar duramente para lograr su reconocimiento jurídico, tarea pendiente en Chile.

\subsection{Recuperar la democracia ${ }^{11}$}

Varios países de la región han retornado los últimos treinta años a la democracia formal o aparente después de haber estado sometidos a regímenes dictatoriales que practicaron terrorismo de Estado, es decir una política de violación sistemática de los derechos humanos, lo que constituyó una forma de Estado fundado en ideas neoliberales. Como consecuencia de ello, miles de personas fueron detenidas y desaparecidas por agentes del Estado, miles encarceladas sin fundamento ni orden judicial, miles torturadas, perseguidas, despedidas de sus empleos, exiliadas y muertas por razones ideológicas y con el propósito de instalar un modelo social y económico determinado, avasallando las conquistas económicos y sociales que tímidamente habían conseguido los pueblos, y suspendiendo sus derechos esenciales y libertades fundamentales. Las heridas dejadas por estos regímenes denominados de seguridad nacional aún no se han cerrado debido a la incapacidad de los gobiernos democráticos por realizar la justicia, perseguir a los criminales y reparar el mal causado ${ }^{12}$, a lo que debemos agregar el fenómeno propio del capitalismo, la dictadura económica a que nos referimos más arriba.

11. Kritz, N (ed.), ( 199)5), Transitional justice. How Emerging Democracies Reckon with Former Regimes. Washington, United States Institute of Peace Press, 3 vol.

12 López Dawson, C. (1992),,, Presentación, en López Dawson, C, editor, Las deudas de la Transición, Santiago. Editora Nacional de Derechos Humanos. p.18 y ss. 


\subsection{Estado de derecho y neoliberalismo}

El Estado de Derecho es, a partir de la Convención de San Francisco de 1945, el respeto de la ley en el contexto del respeto de los Derechos Humanos. Sin embargo, la dictadura militar impuso un ordenamiento jurídico y un sistema económico determinado. Es este contexto en el caso de Chile, se impone una Constitución Política inspirada y estructurada en torno a la ideología neoliberal ${ }^{13}$.

Cuando se dice que la ley debe primar sobre consideraciones personales entonces estamos hablando de Estado de Derecho. En la antigüedad hay antecedentes de la idea de Estado de Derecho y en la propia literatura griega de entonces se hacen referencias al valor de la ley sobre el capricho del gobernante. Los filósofos griegos antiguos se pronunciaron a favor de gobierno regido por el Derecho. El ideal político de Platón, en su obra La República, es una poli donde "el Derecho gobierne a los que gobiernan", porque entonces fructificará todo el bien que los dioses tenían destinado a las comunidades genuinas.

Aristóteles también planteó la necesidad del gobierno de las leyes por sobre el gobierno de los hombres. La democracia ateniense fue el modelo de una poli gobernada por el Derecho. En la Edad Media, al perfilarse las características de racionalidad de la ley frente a los caprichos de la voluntad despótica, se agregaron otros elementos a la concepción del Estado de Derecho, tales como los valores de justicia y de bien común y Santo Tomas de Aquino fundamenta el derecho de rebelión y el tiranicidio cuando el gobernante se aparte de tales principios.

En el siglo XVII, durante la primera revolución burguesa de 1669, en Gran Bretaña se reconoció el principio de la supremacía de la ley, al oponerse sus habitantes al poder arbitrario, acordando entonces establecer el sometimiento de todos, por igual, a la ley. De esta manera, rige el principio del gobierno de las leyes, las que deben ser racionales y justas y su formalización democrática, elementos que sirvieron como antecedentes a la formulación del Estado de Derecho. Ello, por cierto, no impidió que la sociedad siguiera legalmente dividida en clase sociales estamentales. Habrá que esperar cien años para que la revolución de la

13 Nogueira A, H.( 1993), Manual de Educación Cívica, Santiago de Chile. Educación para la Democracia. Participa y Editorial Andrés Bello. Tercera edición, pág. 104. 
Independencia de los Estados Unidos de América, primero y luego al Revolución Francesa pusieran fin a la discriminación legal.

\subsection{Atributos esenciales de un Estado de Derecho en el siglo XXI}

No todo Estado que tiene una normativa legal es un Estado de Derecho, ya que los Estados autocráticos de tipo totalitario o de tipo autoritario también se rigen por normativas jurídicas. Para que un Estado sea efectivamente un Estado de Derecho es necesario que reúna los siguientes atributos o características esenciales de acuerdo con lo prescrito por el Derecho Internacional ${ }^{14}$ :

Tanto gobernantes como gobernados están sometidos a la Constitución y las leyes. Estas tienen que ser expresión auténtica de la soberanía del pueblo a través del órgano constituyente o legislativo elegido democráticamente.

En el Estado de Derecho hay distribución del poder en distintos órganos y funciones que desarrollan actividades diferenciadas a través de órganos ejecutivos, legislativos, judiciales, de control, con el objeto de evitar abusos de poder o actos arbitrarios.

La concentración del poder político grafica la inexistencia del Estado de Derecho. Del mismo modo, no hay Estado de Derecho sin tribunales de justicia que gocen de autonomía e independencia respecto del poder político.

El Estado de Derecho es una parodia cuando no hay elecciones libres, competitivas, pacíficas y reguladas por la ley para los cargos de autoridad y cuando además la estructura social y legal impide la participación de todos con igualdad de oportunidades como sucede con los sistemas binominales y los quórums calificados.

El Estado de Derecho necesita el control jurisdiccional de la administración para sancionar los actos ilegales que pueda cometer la autoridad. De manera que carece de Estado de Derecho un país en el que las autoridades poseen poderes

14 Carta de Naciones Unidas, Declaración Universal de Derechos Humanos, Pacto Internacional de Derechos Civiles y Políticos, y Cláusula Democrática. 
políticos discrecionales contra los cuales no se pueda actuar eficazmente ante la jurisdicción.

\subsection{El control y responsabilidad de los gobernantes}

El Estado de Derecho también exige que los gobernantes puedan ser fiscalizados y que pueda hacer efectiva su responsabilidad.

Los controles son de dos tipos: verticales y horizontales.

Los controles verticales son los que se producen de abajo hacia arriba a través del control ciudadano de la actuación de los gobernantes, y en los que se exige la responsabilidad política. Ello es posible solo en un marco de libertad y de acceso de los ciudadanos a los medios donde se pueda ejercer libre y responsablemente el derecho a la crítica política de los gobernantes.

El control horizontal se refiere al auto control estatal, el que es desarrollado entre los distintos órganos estatales (ejecutivo, legislativo y judicial).

Sin la existencia de mecanismos de control no seria posible exigir la responsabilidad civil, penal, administrativa y política de las autoridades.

La efectiva vigencia, protección y fomento de los derechos humanos constituye el principio y fin básico de todo Estado de Derecho.

No hay verdadero Estado de Derecho sin garantía efectiva, a través de acciones o recursos jurídicos eficaces para la vigencia de los derechos humanos reconocidos tanto en la Constitución Política como en la Declaración Universal de los Derechos Humanos, sus Pactos complementarios de Derechos Civiles y Políticos y de Derechos Económicos y Sociales, y demás instrumentos internacionales vigentes.

\section{Reafirmación histórica del principio de legalidad}

Con el desarrollo y expansión de las Constituciones en la Edad Media con surgimiento de las cartas y fueros, especialmente locales, las cuales contenían 
privilegios y garantías por su propia condición para diferentes sectores se va reafirmando la antigua idea de una norma común superior. Estas cartas regulaban la existencia de los burgos, marcando los derechos y garantías correspondientes al pueblo, fundada su vigencia en el principio de legalidad.

El constitucionalismo moderno parte con la Declaración de Independencia de los Estados Unidos de América seguida por la Constitución de Filadelfia de 1787 y luego por la Revolución Francesa y las emancipaciones o independencia americanas consideradas como revoluciones liberales del siglo XVIII hasta finales del siglo XIX, todo lo cual fue respuesta al Antiguo Régimen. Chile conoció un largo proceso de construcción Constitucional que incorporo desde el principio valores de la ilustración.

\subsection{Origen y características de la Constitución de 1980}

Fue generada por una comisión de juristas de la dictadura cívico militar y plebiscitada fraudulentamente, sin ninguno de los requisitos necesarios de aprobación ${ }^{15}$. Esta Constitución expresa una concepción conservadora del poder político que limita, en gran medida, la soberanía popular, y los derechos humanos, especialmente los económicos, sociales, y otorga carácter constitucional al sistema económico neoliberal, utilizando para ello quórum elevado, por encima de la simple mayoría, para la aprobación de leyes económicas o que inciden en materia de valores impuestos por la dictadura cívico militar en la Constitución, y estableciendo un sistema electoral denominado binominal que impide el seguimiento de nuevos actores políticos y que le otorga a la minoría la misma fuerza electoral que a la mayoría.

\subsection{La constitución política y los derechos y deberes}

Todo ordenamiento jurídico, de cualquier país sin excepción, presenta un

15 Atria, F., (2013), La Constitución Tramposa, Santiago, Lom Ediciones, ,pag, 6 y siguiente. 
ordenamiento escalonado, el cual puede ser graficado a través de la denominada pirámide normativa:

En el vértice superior de esta "Pirámide" está la Constitución (o "Carta Fundamental") y los tratados internacionales ${ }^{16}$; debajo siguen las leyes que de acuerdo con el ordenamiento jurídico, sea o no democrático, pueden tener distintas jerarquías, por ejemplo las leyes de rango constitucional (están inmediatamente debajo de la Constitución), las leyes de quórum calificado siguen más abajo, las leyes de quórum simple, etc., el establecimiento de quórums superiores al $51 \%$ para la aprobación de leyes se traduce en la practica en el control de la minoría en la generación de leyes; después están los Decretos (también presentan jerarquía), uno de ellos son los decretos supremos (firmados por el Presidente de la República), los decretos exentos (exentos del registro en la Contraloría General de la República); más abajo vienen las Resoluciones; los Instructivos; y los Fallos Judiciales. Los quórums reflejan el grado democrático de cada constitución.

- El orden jerárquico normativo indica en primer lugar, que es el marco en el cual se desenvuelve el orden jurídico (conjunto de leyes) lo que implica que una ley no puede contradecir o negar lo que la Constitución dispone, la ley (no puede sobrepasar a la Constitución). Si una ley lo hace entonces puede ser declarada inconstitucional por un tribunal de oficio o por los "recursos de inconstitucionalidad", los que son resueltos, a partir de la reforma Constitucional, por el "Tribunal Constitucional".

- Siguiendo el modelo clásico, la Constitución vigente contiene los derechos y los deberes de las personas.

- También la Constitución establece un orden institucional fundado en el principio de separación de poderes, es decir, un poder que legisla, un poder que administra y un poder que hace justicia, dando origen a tres tipos de instituciones: legislativas, administrativas y judiciales. Montesquieu autor del "Espíritu de las leyes” escribió al respecto.

16 Sobre este punto existe una amplia discusión, en especial sobre la jerarquía de normas, unos estiman que la Constitución está por encima de cualquier norma, otros que los tratados internacionales de derechos humanos tienen carácter supraconstitucional, en tanto otros estiman que ambas normas tienen la misma jerarquía Véase al respecto: Verdugo, S, ( Julio 2010), Entre la responsabilidad internacional del Estado y la supremacía de la Constitución, una perspectiva para enriquecer el debate.en Revista Actualidad Jurídica N²2, Pp. 55-102. 
- La Constitución establece como se originan estas instituciones, cuales son sus competencias, como se hace efectiva las responsabilidades de sus integrantes. Ej: establece que el Presidente de la Republica será electo cada cuatro años, establece la elección de senadores y diputados, etc.

- La Constitución contiene valores que expresan las ideas politicas de sus autores y algunos sobre los que la ciencia política y constitucional comparten, como por ejemplo el Estado constituido de distintos elementos clásicos como el territorio, la población y la institucionalidad y otros como los fines del Estado, que son los "valores" que comparten los constituyentes.

- La Constitución chilena es una Constitución de inspiración supuestamente cristiana; trae en el libro primero ideas que se le atribuyen al cristianismo (Ej. la idea de los derechos de la persona humana como derechos anteriores al Estado, situación que es absolutamente discutible en doctrina jurídica pero que es postulado por las doctrinas con fundamento religioso). Tales valores están puestos alli por quienes redactaron la primera Constitución, en una época de la historia de Chile sometidos a la negación de los derechos fundamentales.

La Constitución Política chilena era en su origen una Constitución llamada de seguridad nacional, que establecía una idea del enemigo del orden jurídico, de la libertad, de los principios fundamentales de la sociedad, y a ese enemigo había que excluirlo, y así se estableció en el Art. $8^{\circ}$ la exclusión de ideas políticas y en el $9^{\circ}$ de esa Constitución el concepto de terrorismo y, por esta vía, la prohibición a los terroristas de participar en la vida política, de tener derecho a ser rehabilitados (en el concepto penal de la palabra) en caso de ser condenados. Esto va a desaparecer en la primera reforma (1988), donde se incorporó un artículo a la constitución (Art. 5, inciso $2^{\circ}$ ) que señala que los Derechos Humanos vigentes reconocidos en instrumentos internacionales son también parte de la Constitución de manera que tienen rango Constitucional.

Los valores contenidos en la Constitución, inciden en el conjunto del ordenamiento jurídico, se traspasan al resto de las normas jurídicas y de hecho las normas jurídicas que le son contrarias pueden ser inaplicables si así lo declara un juez. 
Los valores entonces emanan de la Constitución y al mismo tiempo del conjunto de normas y por tanto establece el modo en el que la sociedad debe comportarse.

En el Estado de Derecho, lo que rige es la ley, y la ley otorga seguridad jurídica. La vigencia de la ley está contenida en un principio llamado "Principio de Reserva" o "Principio de Legalidad". Esto quiere decir, que las actuaciones del aparato del Estado tienen que ceñirse a lo que la ley señala, y por consiguiente, ninguna actuación puede ser contraria a la ley. En el Derecho público sólo se puede hacer lo que la ley permite, lo que la ley señala.

La Constitución Chilena dedica el capítulo III a artículos del 19 al 23 a regular los derechos humanos y los deberes fundamentales y específicamente el artículo 19 enumera los derechos protegidos o amparados por el texto fundamental, haciendo una descripción general de los mismo, por su parte, los artículos 20 y 21 establecen los medios procesales para la tutela, reclamación y consagra los recursos de protección y de amparo. Estos pueden verse afectados en los Estados de excepción Constitucional (artículo 39 a 45), que son reclamados por la autoridad política en supuestos de guerra externa o interna, conmoción interior, catástrofe, emergencia y calamidad pública. Importancia superior tiene el artículo $5^{\circ}$ contempla que la soberanía reside esencialmente en la nación, pero cuyo ejercicio es limitado por el respeto de los derechos esenciales de la persona, lo que es complementado por el articulo $19 \mathrm{~N}^{\circ} 26$ que señala que estos derechos no pueden ser afectados en su esencia.

Artículo $5^{\circ}$ de la Constitución Política del Estado de Chile

"La soberanía reside esencialmente en la Nación. Su ejercicio se realiza por el pueblo a través del plebiscito y de elecciones periódicas y también, por las autoridades que esta Constitución establece. Ningún sector del pueblo ni individuo alguno puede atribuirse su ejercicio".

"El ejercicio de la soberanía reconoce como limitación el respecto a los derechos esenciales que emanan de la naturaleza humana, Es deber de los órganos del Estado respetar y promover tales derechos, garantizados por esta Constitución, así como por los tratados internacionales ratificados por Chile y que se encuentra vigente". 
Esto significa que el Estado debe resguardar estos derechos de la naturaleza del hombre, por tener el más alto nivel de jerarquía jurídica del Estado de Derecho, es por eso que el Estado está limitado, estos derechos le ponen limitaciones al ejercicio de la soberanía.

\subsection{El derecho internacional de los derechos humanos y el derecho constitucional}

Las normas internacionales de derechos humanos vigentes ${ }^{17}$ que se incorporan a la legislación nacional vienen a especificar el contenido del inciso 2 del artículo quinto de la actual Constitución, según el cual las potestades de las autoridades instituidas en dicha Carta tienen, en el ejercicio de la soberanía, "como limitación el respeto a los derechos esenciales que emanan de la naturaleza humana", derechos reconocidos en diversos tratados actualmente vigentes, colocando de esta manera la legislación nacional acorde con el avance del derecho internacional contemporáneo que considera al individuo un nuevo sujeto del Derecho Internaciona $1^{18}$ y una de las preocupaciones fundamentales de la Comunidad Internacional, pues se considera que el reconocimiento internacional y la protección de los Derechos Humanos de todos los miembros de la comunidad humana, son esenciales para el mantenimiento de la paz y el orden internacionales ${ }^{19}$. En el Preámbulo de la Carta de las Naciones Unidas los Estados Miembros afirman "su fe en los derechos fundamentales del hombre, en la dignidad y el valor de la persona humana"; por su parte el artículo 55 párrafo c) de la Carta compromete a la Organización a promover "el respeto universal a los

17 Los Pactos Internacionales de Derechos Civiles y Políticos y de Derechos Económicos, Sociales y Culturales se encuentran en vigencia internacional, el primero desde el 23 de marzo de 1972 y el segundo, desde el 3 de enero de 1976. El Pacto de Derechos Civiles y Políticos fue ratificado por Chile el 10 de febrero de 1972, promulgado como ley de la República mediante decreto supremo No. 778, de 30 de noviembre de 1976, y publicado el 30 de abril de 1989, 13 años después de haberse ordenado su publicación. El Pacto Internacional de Derechos Económicos, Sociales y Culturales fue ratificado el 10 febrero de 1972 y promulgado y ordenada su publicación como ley de la República en el Diario Oficial del 19 de mayo de 1989.

18 Comisión Andina de Juristas, Protección de los Derechos Humanos, Lima, pp. 22.

19 Carta de las Naciones Unidas, artículo 1. 
derechos humanos y a las libertades fundamentales de todos, sin hacer distinción por motivos de raza, sexo, idioma o religión, y la efectividad de tales derechos y libertades", propósitos para cuya realización el artículo 56 prevé que los estados miembros se comprometen a tomar medidas, conjunta o separadamente, en cooperación con la Organización ${ }^{20}$.

\subsection{Los limites de la soberanía}

Es indudable que más allá de la discusión filosófica sobre si el Derecho es anterior o no al Estado, el Derecho surge después de los hechos y es creado por la acción del hombre y su contenido es variable, pues depende de la voluntad de los creadores y por ello sólo será válido en cuanto nazca de una forma que confiera validez, es decir, cuando procede de una forma reconocida ${ }^{21}$. Sin embargo una vez creado es también indudable que en materia de Derechos Humanos adquiere un carácter progresivo cuyo respeto le da o no legitimidad al respectivo orden jurídico ${ }^{22}$.

Ahora bien, la comunidad internacional reconoce el carácter obligatorio del derecho internacional y por lo tanto las limitaciones que le impone a la soberanía nacional. En materia de Derecho Internacional la soberanía Estatal tiene las siguientes características: a) externa, que comprende el derecho de cada Estado a determinar libremente sus relaciones con otros Estados o con otro tipo de identidades sin restricciones o control por parte de otros Estados, sometidos naturalmente a los términos de la Carta de las Naciones Unidas que establece los principios de la paz internacional y de la promoción de los Derechos Humanos; b) carácter interno o político, que consiste en el poder de cada Estado para establecer su condición política y proveer asimismo su desarrollo económico, social y cultural; y, c) por último, el carácter territorial, que importa el ejercicio del Estado de su autoridad exclusiva sobre las personas y bienes materiales que

20 Carrillo Salcedo, A. (1969), Soberanía del Estado y el Derecho Internacional. Madrid. Techos, p. 43.

21 Naciones Unidas, Asamblea General, Comisión de Derecho Internacional.- Documento a/6306/ Re. 1pp. 80.81. 22 Sorensen, M., ed. Manual de Derecho Internacional Público. México, Fondo de Cultura Económica, 1981, p. 151. 
se encuentran dentro, debajo o por encima de su territorio. ${ }^{23}$

Cada uno de los caracteres de la soberanía se encuentra expresamente reconocido en la Carta de las Naciones Unidas y en los Pactos Internacionales de Derechos Humanos y constituyen a su vez un reconocimiento de la existencia de la soberanía y una determinación de sus limitaciones. La soberanía externa es el basamento del derecho internacional convencional- de manera tal que un Estado no puede desconocer una obligación libremente contraída sin negarse a sí mismo. La Corte Internacional de Justicia afirmó en su dictamen sobre la validez de ciertas reservas a la Convención para la Prevención y Sanción del Delito de Genocidio, que un Estado no puede quedar obligado en sus relaciones convencionales sin su consentimiento ${ }^{24}$. Pero, al mismo tiempo, al obligarse la soberanía del Estado quedará, por una parte, limitada, toda vez que debe cumplir con ella, y por otra, su soberanía quedará reafirmada ${ }^{25}$.

La soberanía interna o política tampoco es ilimitada, toda vez que la Carta de las Naciones Unidas establece dos limitaciones fundamentales: La mantención de la paz y la observancia de los Derechos Humanos y libertades fundamentales ${ }^{26}$, sin perjuicio que además los individuos pueden impetrar en su favor ante los tribunales, los principios del Derecho Internacional. En materia de Derechos Humanos la Comunidad Internacional ha establecido su derecho a inmiscuirse en los asuntos internos que se refieren a las violaciones de Derechos Humanos. La doctrina también reconoce tales limitaciones por cuanto se sostiene que "en ningún ordenamiento jurídico es ilimitada la autonomía de la voluntad de sus sujetos, ya que ello supondría la negación del propio ordenamiento y aunque la soberanía de los Estados constituya la base de la sociedad internacional y un principio Constitucional de Derecho Internacional, es indudable que los conceptos abstractos de libertad y soberanía absoluta de los Estados son incompatibles con la existencia misma de la sociedad internacional. En todo grupo social la libertad de pactar tiene límites y existen normas jurídicas y principios morales que la ley

23 Sorensen, op. cit. p. 152.

24 CPJI, serie A, No. 1, citado por Remiro Brotons, A., (1982), Derecho Internacional Público, Madrid, Tecnos, p. 83 .

25 Carrillo Salcedo, op.cit. p. 186-187.

26 Oppenheim, L., (1961), Tratado de Derecho Internacional Público. Barcelona, Bosh, p. 315 del volumen I del I. 
no permite a los individuos desconocer ni modificar por medio de acuerdos" 27 . Además, hoy en día se postula el derecho de injerencia, es decir el deber que tienen otros Estados de intervenir por todos los medios en aquellos Estados donde se violan masiva y sistemáticamente los Derechos Humanos.

\section{Las características de la Constitución}

Es rígida y autoritaria, pues requiere alto quórum para reformarla y otorga un gran poder al Ejecutivo. Además, dispone la dictación de leyes orgánicas constitucionales para reglamentar algunas de sus disposiciones, y leyes de quórum calificado. Todo ello contribuye a un sistema jurídico pétreo y no democrático.

Contiene Leyes Interpretativas: que son aquellas que no modifican el texto de la Constitución, sino que aclaran y explican el sentido y alcance de una norma constitucional. La Constitución no las define sólo se refiere al quórum necesario para su aprobación, modificación o derogación que deberá ser de los 3/5 de diputados y senadores en ejercicio, debiendo necesariamente pasar por el control previo del T.C. (La C.P. de 1833 reconocía las Leyes Interpretativas, pero fueron eliminadas de la C.P. de 1925 y repuestas más tarde en 1980).

El Tribunal Constitucional es el órgano encargado de fiscalizar que las leyes respeten la supremacía constitucional y está facultado para declarar la inconstitucionalidad de las leyes.

En la Constitución de la República de Chile, se debe distinguir el reconocimiento de dichos derechos, desde un punto de vista subjetivo. (Cap. III art. 19, 20, 21; Cap. II Nacionalidad y Ciudadanía)

En un sentido objetivo, forman parte integrante del Estado de derecho, en cuanto sirven de fundamento al orden político (Cap. I "Bases de la Institucionalidad")

Principio de legalidad. Este principio tiene a lo menos dos formas de expresión o manifestación en nuestra Constitución:

27 Carrillo Salcedo, op. cit. pp. 206 y ss. 
- La idea o el principio de supremacía constitucional (art. $6^{\circ}$ C.P.80).

- La idea o el principio de legalidad (art. $7^{\circ}$ C.P. 80).

Los derechos fundamentales están garantizados, pero sólo algunos tienen un recurso constitucional y en cambio otros son meramente declarativos. Los recursos constitucionales extraordinarios para hacerlos efectivos son el recurso de amparo para el derecho a la libertad, el de protección para varios derechos como a la vida, la integridad física y síquica, y otros económicos, culturales y sociales como el de reunión, asociación, el no ser juzgado por comisiones especiales, el derecho a vivir en un medio ambiente libre de contaminación, el de propiedad, el derecho a ejercer cualquier actividad económica o laboral, etc. Los derechos meramente declarativos son el derecho al trabajo, a la salud y a la educación.

\subsection{Presencia de la constitución en nuestra vida cotidiana}

Condiciona nuestra vida porque permite la máxima concentración de poder económico, al limitar la función reguladora del Estado; no protege nuestros Derechos Humanos, a la salud, educación y otros, ni siquiera a acceder a anticonceptivos de emergencia; concentra el poder político creando una crisis de representación y otorgando poder de veto a las minorías conservadoras; finalmente, permite y estimula la enorme desigualdad económica y social.

El concepto autoritario que está a la base de la Constitución, demostrado por su origen y por algunas de sus normas no democráticas, se contrapone con algunas de sus propias normas. Por ejemplo el artículo $4^{\circ}$ que declara que Chile es una Republica democrática o según el artículo $5^{\circ}$ inciso segundo que ninguna manifestación de la soberanía puede afectar los derechos fundamentales.

La Constitución garantiza el derecho de propiedad y dominio de los medios de producción y el derecho a desarrollar cualquier actividad económica mediante el amparo económico que es la acción que la ley concede a cualquier persona para denunciar las infracciones a la garantía constitucional que protege el derecho a desarrollar cualquier actividad económica que no sea contraria a la 
moral, al orden público o a la seguridad nacional. Es una acción jurisdiccional de carácter conservador, especial y popular, en la que el actor no necesita tener interés actual y que busca proteger la garantía constitucional del artículo $19 \mathrm{~N}^{\circ}$ 21 de la Constitución Política de la República. La ley $N^{a}$ 18.971, en el inciso primero de su artículo único, preceptúa que "Cualquier persona podrá denunciar las infracciones al artículo 19, número 21, de la Constitución Política de la República de Chile".

\subsection{Principales críticas}

Estas son. (a) De carácter político (P. ej. divide la nación, y no expresa los consensos fundamentales de ella; no es verdaderamente democrática y otorga capacidad de veto con los sectores minoritarios); (b) de carácter jurídico. Fue generada ilegítimamente, es arcaica y no corresponde a las concepciones del constitucionalismo contemporáneo y sus reformas no la validan.

La Constitución puede ser criticada por imponer un modelo económico, político y social sin previa consulta democrática a la población y luego porque favorece la concentración del poder económico y político, inspirada por una parte en la constitución franquista de carácter fascista y por otra en la doctrina neoliberal, la que ha sido extremada mediante la mercantilización por medio de la privatización de la totalidad de los servicios básicos: Agua, luz, gas, transporte, etc., de los servicios de Salud: Isapres y prestación privada al sistema de subvención pública; Previsión: AFPs; Obras públicas: Infraestructura vial, transporte publico; Educación: subvenciones y privatización de todos los niveles de educación. Es lo que se ha denominado la reducción del estado al servicio del lucro privado.

Organismos de Naciones Unidas han descrito la situación social chilena mostrando altos índices de Inseguridad ciudadana/ Altos índices de inseguridad Humana (PNUD, 1998)/ Privatismo /centramiento en familia y desconfianza en la comunidad / competencia / ansiedad y depresión.

La educación chilena ha confiado en una ideología que da una importancia indebida a los mecanismos de mercado para manejar los procesos de enseñanza. 
(aprendizaje (OCDE, 2004 pag. 290).)

Se sostiene por los críticos del modelo que la estrategia de construcción de subjetividad del neoliberalismo une en su desarrollo dos tareas, hasta ahora separadas: la generación de plusvalía y la construcción de conciencias (legitimación - gobernabilidad). Es decir, el modelo económico lleva consigo el modelo político, lo que tiene consecuencias sociales complejas.

Los principales instrumentos para permitir que el modelo se imponga sin contrapeso es primera la dictación de leyes de quórum calificado durante los últimos días de la dictadura, lo que junto al sistema binominal permite que la minoría imponga su voluntad a la mayoría por cuanto para reformar las disposiciones señaladas se requiere quórums superiores a la mayoría simple.

El sistema de quórum ideado por Jaime Guzmán e inspirado en el nazi y franquista Carl Schmitt, transforma a la constitución vigente en una pieza pétrea imposible de cambiar por via democrática, via que, además, no contempla la constitución vigente.

\subsection{Reformas y una nueva Constitución ${ }^{28}$}

Las reformas constitucionales han sido, en mayor o menor grado, una de las banderas de campaña de los candidatos presidenciales en Chile, como Eduardo Frei, Marco Enríquez-Ominami, Jorge Arrate, Michelle Bachelet, Ricardo Lagos, etc., quienes han coincidido en la mayoría de las modificaciones a la Carta Fundamental, con excepción de quien fuera luego Presidente de la República, Sebastián Piñera, quien era claramente proclive a no modificar la actual Constitución.

Hacia una Constitución fundada en la democracia: Una Constitución política como expresión de la voluntad de la comunidad, solo puede ser democrática. Ese espíritu anima la primera y a las constituciones siguientes:

28 http://www.lanacion.cl/prontus_noticias_v2/site/artic/20090630/pags/20090630002334.html 
"La soberanía recae en el pueblo, o sea soberanía popular, y esta jamás se delega, siempre permanece en el pueblo" Jean Jacques Rousseau.

Artículo 1."Todos los seres humanos nacen libres e iguales en dignidad y derechos y, dotados como están de razón y conciencia, deben comportarse fraternalmente los unos con los otros". Declaración Universal de Derechos Humanos.

Desde 1989 la Constitución de 1980 ha tenido más de cien modificaciones, siendo fundamental la que modificó el citado artículo $5^{\circ}$, sin embargo su estructura, es decir, el modo como concibe la soberanía, su concepción de los derechos humanos, de los poderes del Estado y sus relaciones, el carácter constitucional que se otorga al sistema económico neoliberal mediante el principio de la subsidiariedad, del papel de veto del Tribunal Constitucional, expresión también del binominalismo antidemocrático, frente a los acuerdos de los representantes políticos, su doctrina sobre las leyes constitucionales, y su extrema rigidez, etc. ha permanecido incólume. En resumen, los quórums no democráticos que impuso la dictadura siguen allí.

La Constitución establece como definitivo un orden político, económico y social no sólo en su texto central sino a través de sus capítulos adjuntos que son las leyes orgánicas constitucionales, parte fundamental de este sistema. De este modo, la legislación electoral con el monstruoso binominalismo y sus arbitrarios distritos electorales, las normatividad sobre la minería que puso fin a la nacionalización, la excesiva influencia presidencial en la formación de las leyes, en contraste al desconocimiento de la voluntad ciudadana, y otras instituciones centrales forman parte de este sistema constitucional. En este sentido la Constitución chilena es, teórica como prácticamente, una de las constituciones más extensas y detalladas del mundo.

El referido orden político, económico y social ha sido rechazado por la mayoría de la ciudadanía, como lo manifiestan los mejores estudios de opinión pública desde el informe del PNUD de 1998. No es aceptable ni sustentable en el tiempo una Constitución cuyas instituciones fundamentales no son aceptadas por los ciudadanos por que no expresa sus consensos básicos.

La creciente apatía política -especialmente de los jóvenes-, que no es 
sustentable en el tiempo, se debe en importante medida a la obstinación de mantener una Constitución y un sistema electoral, que no ha logrado legitimarse, lo que no se resolverá mientras no cambie. Expresión de lo expuesto es el abstencionismo en las pasadas elecciones municipales, de que constituye un claro problema para el ejercicio de los derechos políticos y podría sostenerse que vacía de contenido la democracia.

La tendencia a la abstención electoral es un fenómeno creciente en muchas partes y también en nuestro país, lo que se manifiesta, según encuestas y recientes votaciones, en el malestar ciudadano respecto de las actuaciones de políticos y medidas no adecuadamente compartidas del sistema político.

El argumento de que la Constitución asegura la gobernabilidad es un sofisma, y una versión actualizada del argumento de la dictadura de que solo ella podía asegurar el orden y evitar el caos. Una gobernabilidad que no se funda en la legitimidad, en lo que Habermas llama "el patriotismo constitucional" tiene sus días contados, se irá deteriorando porque la Constitución se ha convertido en una jaula de hierro para una autentica democracia y para el cambio social político, económico y social.

La historia muestra que cuando se produce y profundiza esta falta de representatividad, esta crisis de representatividad entre los ciudadanos y el sistema constitucional, se generan profundas crisis políticas y al final la Constitución es cambiada. El hecho que un sector social y político quiera mantener este sistema no es suficiente para su conservación y reproducción. Más temprano que tarde habrá que elaborar una nueva constitución y un sistema jurídico integral moderno. El orden social, jurídico político y social heredado está, del mismo modo como lo estuvo el sistema oligárquico que llevó a la sociedad a una situación de profunda crisis y decadencia en las primeras décadas del siglo pasado.

\subsection{Educación cívica y una nueva cultura}

Nadie tiene facultad alguna para imponerle a los demás su modo de pensar, sus doctrinas o sus convicciones. En ese principio se fundamenta la democracia, A 
pesar de las reformas constitucionales la Constitución Política del Estado no representa la voluntad soberana del pueblo chileno. Una participación informada en el debate constitucional requiere impartir educación cívica y construir una nueva cultura política fundada en la tolerancia.

El término "Democracia", se refiere al "Demos-Kratos" («demos» = pueblo, «kratos»= gobierno o poder). La traducción tradicional entonces resulta en «gobierno del pueblo» o «poder del pueblo». La palabra «Democracia» proviene de la Antigua Grecia, específicamente en la Atenas del a.C. (en el siglo de Pericles). Por ello se la denomina frecuentemente como Democracia Ateniense. Tuvo una vida relativamente prolongada en comparación con las democracias liberales actuales, pues puede hablarse del período democrático en Atenas desde las reformas de Clístenes alrededor de 510 a.C. Hasta la supresión de las instituciones democráticas a causa de la hegemonía macedonia en 322 a.C..

El "gobierno del pueblo" en Atenas, consistía en una asamblea de todos los ciudadanos libres que elegía cada año a diez estrategas (o generales), uno por cada una de las diez tribus ciudadanas. Los estrategas tenían a su cargo preparar las expediciones de guerra, recibir a los enviados de los demás pueblos y dirigir la política. Tenían derecho al voto los varones libres mayores de 30 años.

El término "democracia" también se utiliza ampliamente no solo para designar una forma de organización política, sino una forma de convivencia y organización social menos vertical, más horizontal, con relaciones más igualitarias entre sus miembros. Por ello se puede sostener que es una forma de vida. En este sentido es habitual el uso del término "democratización", como por ejemplo la democratización de las relaciones familiares, de las relaciones laborales, de la empresa, de la universidad, de la escuela, de la cultura, etc. En todo caso, la democracia es un sistema político que permite el funcionamiento del Estado, en el cual las decisiones colectivas son adoptadas por el pueblo mediante mecanismos de participación directa o indirecta que le confieren legitimidad.

Los filósofos ilustrados del siglo XVIII encuentran la esencia de la democracia en el derecho del pueblo a designar y controlar el gobierno de la nación (Rousseau, Locke, Montesquieu). La democracia adopta variadas formas, siendo fundamental que las personas que la integran la comunidad tengan la posibilidad de influir de manera legal en el proceso de toma de decisiones. 
La democracia se define también a partir de la clasificación de las formas de gobierno realizada por Aristóteles en tres tipos básicos: monarquía (gobierno de uno), aristocracia (gobierno de pocos), democracia (gobierno de muchos o todos).

El concepto peyorativo o practico de la tiranía de la mayoría, por el cual se pueden afectar los derechos de las minorías, ha sido superado por el derecho internacional de los Derechos Humanos, lo que fue recogido en la reforma del citado artículo $5^{\circ}$ que lo impide al señalar que el limite del ejercicio de la soberanía son los derechos fundamentales. Por ello es necesario tener presente que como sostiene George Burdeau: "la descripción de la organización constitucional de un Estado, el análisis de su vida política, el estudio de la red compleja de fuerzas que orientan su destino conducen siempre, en definitiva, al examen de la Constitución George Burdeau afirma que la Constitución o estatuto de poder reviste dos aspectos o funciones; uno que se refiere a la naturaleza o sustancia del poder y otro que se refiere a su ejercicio por los gobernantes. Al primero, lo denomina estatutos de la institución estatal o del poder en si mismo y, al otro lo llama estatuto de los gobernantes o del ejercicio concreto del poder".

Debemos concluir que la forma política que mas se acerca a la perfección es aquella en la cual la "Democracia" se asocia con el "Estado de Derecho", entonces, la voluntad de las mayorías y los gobiernos quedan sometidos a un sistema de reglas pre establecidas que obligan a todos, incluyendo al pueblo.

Desde cualquier perspectiva, la ausencia de democracia en el origen y contenido de una Constitución la coloca al margen del debate Constitucional, de manera que éste se recupera cuando la base sobre la cual se encuentra el debate es la democracia. Cualquier otro fundamento constituirá un abuso y un contrasentido.

\subsection{Modos de cambio constitucional}

Las constituciones modernas fundadas en el reconocimiento de los Derechos Humanos se originan en asambleas. El artículo 26 de la Declaración Universal de Derechos Humanos de Naciones. 
Una Asamblea Constituyente es una reunión nacional de delegados del pueblo no representantes elegidos o designados con el objetivo específico de determinar las reglas de funcionamiento del Poder Público como fundamento de su sistema político y plasmar a través de un pacto político en una Constitución fijando reglas para la construcción de un nuevo Estado y de convivencia entre éste y la sociedad. ${ }^{29}$

En la actualidad podríamos hablar de dos tipos de asambleas constituyentes: Asamblea Constituyente no institucionalizada: Es aquella asamblea nacida espontáneamente, sin regulación previa. Por ejemplo, la asamblea de las provincias del Alto Perú de 1825 que dio origen a la República de Bolivia.

Asamblea Constituyente institucionalizada: Es aquella que se encuentra contemplada y regulada por la propia Constitución. Habitualmente, es una organización temporal, electiva, representativa, democrática, pluralista, facultada solamente para reformar el texto constitucional. Tal es el caso del cuerpo previsto en el art. 30 de la Constitución de la República Argentina para toda reforma -total o parcial- del texto de la Ley Suprema, que se forma al solo efecto de ella y se disuelve una vez producida esa enmienda. ${ }^{30}$

La Presidenta Michelle Bachelet convocó a los ciudadanos a participar en un proceso constituyente cuyo objetivo era aprobar una nueva constitución política. Esta convocatoria tuvo una respuesta creciente de los ciudadanos y permitió la participación; la que tendrá por ello el carácter de constituyente en una primera etapa.

Después del proceso que denominaremos de Consulta Constituyente, se hizo entrega a la presidenta un informe con las conclusiones a que llegó un grupo de expertos y las principales propuestas de las Bases Ciudadanas son las siguientes:

- El primer concepto que destaca el CCO es Justicia, la cual debe ser igual para todos y sin sistema de justicia militar. Además, debe ser un sistema probo e igualitario, incluyendo perspectiva de etnia y pueblos originarios. - La Democracia se entiende como el único sistema de gobierno válido. Debe ser participativa e incluir la posibilidad de llevar a cabo plebiscitos

29 Jorge Machicado http://jorgemachicado.blogspot.com/2013/05/aco.html $30 \mathrm{http}: / /$ es.wikipedia.org/wiki/Asamblea_constituyente 
y referéndums, educando sobre este valor y con cargos públicos rotativos y límites en la reelección. Además, se indica que el Estado debe garantizar la participación ciudadana en toma de decisiones.

- En las conclusiones se destaca el respeto por el medio ambiente y conservación, como medida fundamental para cuidar la propia especie humana. Asimismo, se propone nacionalizar nuestros recursos naturales. - La igualdad por su parte, debe ser económica y social, de derechos y de oportunidades. Se entiende como equidad ante la ley, equidad de género, acceso a la justicia, inclusión, igualdad ante los derechos y acceso de oportunidades.

- Otro concepto que se enfatiza en el informe es la Descentralización. Debe haber reconocimiento real de los territorios para que puedan decidir cómo quieren desarrollarse según su realidad, respetando la diversidad de naciones y principios multiculturales, con mecanismos de participación y poder local para la toma de decisiones. La descentralización debe ser a nivel nacional, regional, provincial y comunal, incluyendo una distribución equitativa de los recursos. Las desigualdades intrarregionales deben ser compensadas, considerando la particularidad de distintos territorios

- El respeto a los DDHH debe tener un carácter fundamental, cruzándose con todos los estamentos de Estado, e incorporándose en todo el proceso educacional de formación cívica, incluyendo a las fuerzas armadas.

- El Estado debe ser responsable del resguardo de nuestro patrimonio histórico y cultural, instalando mecanismos de promoción cultural con fines públicos.

- Se deben incluir mayores instancias de participación ciudadana que complementen la democracia representativa y acorten la brecha de ésta con la voluntad popular. Debe haber plebiscitos vinculantes, pudiendo los ciudadanos exigir la realización de un plebiscito, con un número de firmas, siendo estos ajustes y correcciones esenciales para recuperar la confianza de la comunidad en las personas e instituciones que actúan en asuntos políticos

- Una de las propuestas contempladas en el informe contempla la creación de un Congreso unicameral que cumpla la función legislativa y 
fiscalizadora que tiene, agilizando el trámite parlamentario y rebajando los recursos que se gastan al mantener dos cámaras.

- Defensor del pueblo: es una manera eficaz de defender los derechos colectivos del pueblo. Debe ser autónomo con un patrimonio propio y descentralizado para ayudar en la defensa de los derechos ciudadanos contra los abusos de los poderosos y del propio Estado.

- Las FFAA deben estar subordinadas al poder civil para no repetir el quebrantamiento de la institucionalidad. Deben ser democráticas no discriminatorias subordinadas al poder civil, eliminando ley reservada y sin justicia ni previsión especial. De manera tal que los cambios constitucionales solo se legitiman cuando se realizan democráticamente y con respeto de los derechos humanos.

\section{Conclusiones}

Es fácil concluir, que la actual Constitución no es democrática, que no reúne los requisitos de una Constitución propiamente tal, sino que es una Carta Fundamental impuesta por una dictadura cívico militar cuyo objetivo era instalar un modelo de sociedad que niega los Derechos Humanos, lo que le resta legitimidad y lo que es suficiente para exigir su cambio.

$\mathrm{Si}$ bien es cierto que determinados sectores que se oponen al cambio constitucional han expresado su crítica al proceso mismo, no se han atrevido a cuestionar los puntos expuesto en el informe ${ }^{31}$. El proceso histórico del constitucionalismo ha sido de menor a mayor e irreversible. Si bien en sus inicios se incorporan algunas garantías para el reconocimiento de derechos, en especial aquellos que eran más ignorados por los regímenes absolutistas, luego se van ampliando en un proceso progresivo, sin vuelta atrás. Cuando los dictadores tratan de parar la rueda, entonces aparecen al margen del Derecho y arriesgan ser sancionados por la comunidad internacional. El proceso constitucional chileno

31 Lamentablemente este debate se ve empañado por desastres políticos y y atentados criminales. Importantes políticos aparecen denunciados como corruptos, practicando cohecho y al mismo tiempo se producen atentados incendiarios que destruyen la zona forestal y agrícola de país. 
no queda al margen de esa caracterización. El cambio probable será a través de un plebiscito y una asamblea constituyente, o no será todavía.

El fenómeno de la abstención es un riesgo evidente para un proceso constituyente, debilita su base moral. Sin embargo, parece que la necesidad de volver, o más bien dicho, establecer un Estado ético que garantice los derechos y que tenga una institucionalidad no expuesta a la corrupción, podría atraer a los electores para construir una constitución verdaderamente democrática.

Existen fuerzas incuestionables que pugnan por una nueva Constitución y es predecible que el campo de batalla será si esta nueva institucionalidad política se suma a la modernidad incorporando en ella la plenitud de los Derechos Humanos debidamente garantizados, en definitiva, si estos derechos serán realmente respetados y garantizados o solo será un reconocimiento formal, en la medida de lo posible.

\section{Bibliografía}

Carta de San Francisco, Capítulo VII.

Ver por ejemplo Elkin, N, (Noviembre 1994), Las normas internacionales del trabajo y la integración regional económica. en Integración Latinoamericana (Buenos Aires. INTAL), nº 19, 205, Quirós, L, (2013) "La destitución de Fernando Lugo y la crisis politica de los Ejecutivos en America Latina (2000-2012)."

Available at: http://works.bepress.com/ludmila_quiros/8/, y Kersffeld,D.

La UNASUR y su accionar frente a conflictos internacionales: http:// search.proquest.com/openview/9efd2d768b8d03885dd56e55c2a2dc f8/1? pq-origsite $=$ gscholar\&cbl $=27928$

http://dossiergf.wordpress.com/2012/06/22/la-acusacion-contra-lugo-

se-basa-en-cinco-actuaciones-de-su-gobierno-y-pide-un-procesopenal/ 
Stahringer de Caramuti, O, (1998), El MERCOSUR en el Siglo XXI., Buenos Aires, Ediciones Ciudad Argentina, 591 págs. (varios autores, por ejemplo Da Silva, C, Globalización y Regionalismo versus trabajo y desempleo. Notas de fin de milenio, pp. 107-134.). http://www.un.org/womenwatch/daw/beijing/pdf/BDPfA\%20S.pdf Marx, K, (1987), ElCapital, - tomo II, Pág. 154. Marx/Engels “Manifiesto Comunista"

Engels, "principios del comunismo", en http:/www.monografias.com/ trabajos5/tekarl/tekarl.shtml. Marx k, (1857), introducción general a la crítica de la economía política Pág. 11

. Althouser, L, (1968): Montesquieu, la politique et l'histoire; París, PUF, cap. V. También, Kirchheimer, Otto, (1968). Justicia política. Baires. Ed. T. pág. 191

Chile, la Memoria Prohibida, Santiago, Dolmen,. Montealegre Klenner, H,(1979), La seguridad del Estado y los derechos humanos, Santiago de Chile, Dolmen.

Montealegre Klenner, H, (1995), p. 35.

Kritz, N (ed.), ( 199)5), Transitional justice. How Emerging Democracies

Reckon with Former Regimes. Washington, United States Institute of Peace Press , 3 vol.

López Dawson, C. (1992),,, Presentación, en López Dawson, C, editor,

Las deudas de la Transición, Santiago. Editora Nacional de Derechos Humanos. p.18 y ss.

Nogueira A, H.( 1993), Manual de Educación Cívica, Santiago de Chile.

Educación para la Democracia. Participa y Editorial Andrés Bello. Tercera edición, pág. 104.

Carta de Naciones Unidas, Declaración Universal de Derechos Humanos,

Pacto Internacional de Derechos Civiles y Políticos, y Cláusula Democrática.

Atria, F., (2013), La Constitución Tramposa, Santiago, Lom Ediciones, ,pag, 6 y siguiente.

Verdugo, S, ( Julio 2010), Entre la responsabilidad internacional del Estado y la supremacía de la Constitución, una perspectiva para 
enriquecer el debate.en Revista Actualidad Jurídica $\mathrm{N}^{\circ}$ 22, Pp. 55102.

Comisión Andina de Juristas, Protección de los Derechos Humanos, Lima, pp. 22.

Carta de las Naciones Unidas, artículo 1.

Carrillo Salcedo, A. (1969), Soberanía del Estado y el Derecho Internacional. Madrid. Techos, p. 43.

Naciones Unidas, Asamblea General, Comisión de Derecho Internacional.Documento a/6306/ Re. 1pp. 80.81.

Sorensen, M., ed. Manual de Derecho Internacional Público. México, Fondo de Cultura Económica, 1981, p. 151.

Sorensen, op. cit. p. 152.

CPJI, serie A, No. 1, citado por Remiro Brotons, A., (1982), Derecho Internacional Público, Madrid, Tecnos, p. 83.

Carrillo Salcedo, op.cit. p. 186187.

Oppenheim, L., (1961), Tratado de Derecho Internacional Público.

Barcelona, Bosh, p. 315 del volumen I del I.

Carrillo Salcedo, op. cit. pp. 206 y ss.

http://www.lanacion.cl/prontus_noticias_v2/site/artic/20090630/

pags/20090630002334.html

Jorge Machicado http://jorgemachicado.blogspot.com/2013/05/aco.html http://es.wikipedia.org/wiki/Asamblea_constituyente 
